\title{
From Sugar to Nutritional Products - Product Form Development
}

\author{
Theo Ralla§, Roland Schex§, Fabiola Porta, and Christian Schäfer*
}

\begin{abstract}
The formulation of active ingredients into emulsion- and suspension-based delivery systems offers a wide range of opportunities to produce stable and highly bioavailable product forms for their later application in human and animal nutrition. Recent trends in product form development have focused on using renewable and naturally-derived raw materials to meet the increasing consumer demand on sustainable value chains and nutritional products with 'clean labelling'. Therefore, we reviewed chemical fundamentals and application examples of plant-derived protective hydrocolloids with highly potent emulsifying capacity, in particular, modified starches, pectin, and lignosulfonates, for the formulation of vitamins, carotenoids, and other active ingredients.
\end{abstract}

Keywords: Carotenoid · Formulation · Lignosulfonate $\cdot$ Modified starch $\cdot$ Pectin $\cdot$ Vitamin

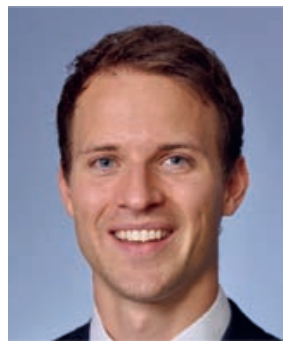

Theo Ralla works as Scientist at DSM Nutritional Products where he serves as project director for infrastructure projects for state-of-the-art process technology of carotenoid formulations. Theo holds a BSc, $\mathrm{MSc}$, and $\mathrm{PhD}$ in food process engineering from the University of Hohenheim in Germany and gained industry experience from Fraunhofer Institute for Interfacial Engineering and Biotechnology, Danone, and Nestlé, as well as academic experience from the University of Massachusetts, Amherst as part of a promos scholarship. During his $\mathrm{PhD}$ he investigated the functionality of innovative saponin extracts to elucidate the structure-function relationship of the naturally-derived saponin Glycyrrhizin used as a surfactant.

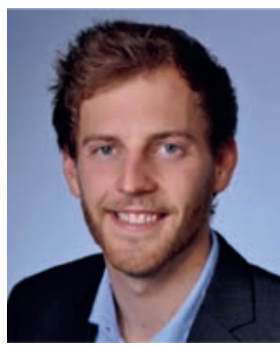

Roland Schex works as Scientist at DSM Nutritional Products, being responsible for research and development of innovative carotenoid product forms for later application in human and animal nutrition. Concurrently, he is undertaking a doctoral research project on the color of carotenoids as steered by (E/Z)-ratios, aggregation, and formulation technology in collaboration with the Hochschule Geisenheim University. Roland holds a MSc in Food Science and Engineering from the University of Hohenheim in Germany and gained industry experience at Meggle, Bahlsen, and KIWA natural life, as well as academic expertise from research stays at the University College Dublin and the University of Costa Rica.

${ }^{*}$ Correspondence: Dr. C. Schäfer, E-mail: christian.schaefer@dsm.com R\&D Center Formulation, DSM Nutritional Products,

Wurmisweg 576, CH-4303 Kaiseraugst

\$Both authors contributed equally

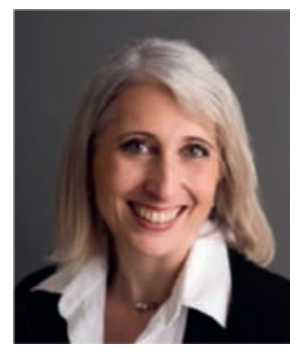

Fabiola Porta works as EMEA Principal Scientist at DSM Nutritional Products, leading the formulation team of Vitamins and Nutritional Lipids. Fabiola holds a MSc Degree in Medicinal Chemistry and Pharmaceutical Technology from the University of Milan, Università degli studi di Milano, and a PhD in Soft Matter Chemistry from Leiden University, the Netherlands. Before starting her career in DSM, Fabiola has worked in the field of nanoencapsulation and bio-nanotechnology in several academic institutes in Switzerland, the latter being the University of Basel where she was a principal investigator in the field of nanodrug delivery.

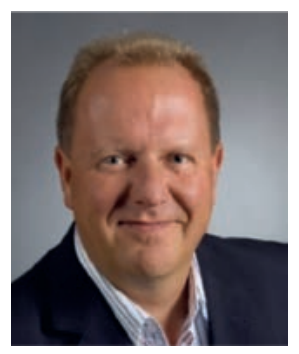

Christian Schäfer works as Principal Scientist at DSM Nutritional Products, being responsible for the development of innovative product forms in the field of vitamins, carotenoids, nutritional lipids, and other health ingredients applying state-ofthe-art and novel formulation concepts \& processes. Trained at Ludwig-MaximilianUniversity Munich as food chemist, he received his $\mathrm{PhD}$ from Hohenheim University. Prior to joining DSM in 2003, he was employed with the Fraunhofer Institute Process Engineering and Packaging (IVV), Freising. He is a member of the German Chemical Society (GDCh) and its working group Food Chemical Society (LChG). Safeguarding results from research via patent applications and shaping strong teams are his passion.

\section{General Introduction to Formulation}

\subsection{Vitamins and Carotenoids}

The article by Marty and coworkers in this issue ${ }^{[1]}$ describes the synthesis of active ingredients and their intermediates via new sustainable routes. Once successfully produced, active substances like vitamins, carotenoids, and their derivatives are not stable against various environmental factors, i.e. light and oxygen exposure, elevated temperatures, and extreme $\mathrm{pH}$-values during processing and storage. Vitamins may degrade during processing and 
storage in food applications. ${ }^{[2]}$ Especially the widely distributed carotenoids, some of which can be converted into vitamin A, an essential nutrient for humans, ${ }^{[3]}$ are prone to $(E / Z)$-isomerization ${ }^{[4]}$ and, thus, susceptible to decomposition. Moreover, fat-soluble vitamins like vitamin $\mathrm{A}, \mathrm{E}$, and D as well as carotenoids as lipophilic crystalline compounds are insoluble in water, resulting in low bioavailability in aqueous systems. ${ }^{[5]}$ For these reasons, pure vitamins and carotenoids need to be formulated into stable and bioavailable delivery systems. Encapsulated and optionally dried oil-in-water $(\mathrm{o} / \mathrm{w})$ emulsions are suitable delivery systems of stable and bioavailable product forms of various fat-soluble vitamins and carotenoids. Furthermore, suspensions, e.g. yielded by high-performance wet-milling of crystalline active ingredients in an aqueous or oily milieu, are also widely used delivery systems. ${ }^{6]}$ Interfaces between the internal phase, e.g. comminuted crystalline particles or oil droplets in the range of 100-2000 nm, and the continuous phase need to be formed with emulsifiers or amphiphilic hydrocolloids, stabilizing the dispersed system and, thus, protecting the active ingredients from oxidation and re-crystallization. ${ }^{[7,8]}$

\subsection{Synthetic vs. Naturally-derived Emulsifiers}

Emulsifying agents are surface-active substances that i) facilitate emulsion formation by e.g. reducing interfacial tension and ii) promote emulsion stability. Overall, emulsifiers can be distinguished into synthetic and naturally-derived compounds. According to patent literature, emulsifiers such as sorbitan esters (Spans) and polysorbates (Tweens) today still serve as reliable emulsifiers providing suitable product forms for the coloration of foodstuffs, in particular beverages. ${ }^{[9,10]}$ However, negative effects of such food additives on the gut microbiota are discussed in relation with the irritable bowel syndrome (IBS), a phenomenon with a prevalence of $10-15 \%$ in Western countries and resulting in the exclusion of polyols in diets for IBS patients. ${ }^{[11]}$ In addition, the use of naturally-derived dyes has been increasingly stimulated and used as a marketing strategy, leading to a replacement of azo dyes in various foods and beverages. ${ }^{[12]}$ This increasing consumer demand for 'clean' naturally-derived compounds in food directs the choice of suitable emulsifying and stabilizing agents - often designated as 'wall material' in microencapsulation techniques.

Surface-active agents (surfactants) are commonly used to improve the wettability of hydrophobic droplets, allowing an efficient encapsulation of the active ingredients. ${ }^{[13]}$ Among this group of substances, hydrocolloids play a major role in the stabilization of interphases due to their emulsifying properties. Hydrolyzed proteins such as gelatins have been largely used to encapsulate nutrients to prevent an undesired loss of activity. Gelatins are watersoluble mixtures of proteins and peptides obtained by hydrolysis of collagen, a fibrous protein widely present in tissues such as skin, bones, and cartilages in several animal species, e.g. cattle, poultry, swine, or fish. ${ }^{[14]}$ To obtain a surface-active hydrocolloid, a chemical treatment is necessary to destabilize the tertiary structure of collagen and, consequently, convert the water-insoluble collagen into water-soluble gelatins. ${ }^{[15]}$

In the last 20 years, especially the high acceptance of plantderived foodstuffs by consumers has resulted in a growing market for vegetarian products. As a result, intense research for the replacement of gelatins and their numerous applications with plantderived hydrocolloids has been reported. ${ }^{[16]}$ In addition, the trend to naturally-derived emulsifiers and the growing interest in halal and kosher products has driven the attention of the food ingredient industry into plant-based solutions for encapsulation techniques. Important 'label-friendly' biopolymers from renewable sources being applied in various encapsulation techniques for food systems are modified starches, ${ }^{[17]}$ gums, e.g. gum acacia, ${ }^{[18]}$ and extracted plant proteins, e.g. from lupine,[19] canola, ${ }^{[20]}$ rice, ${ }^{[21-23]}$ soy, ${ }^{[24]}$ and their derivatives, as well as phospholipids. ${ }^{[25]}$ Suitable product forms in the field of animal nutrition have been provided by the introduction of plant-derived lignin derivatives, e.g. lignosulfonates are excellent examples of high-performing hydrocolloids with emulsifying and stabilizing properties obtained from a renewable source.[26,27]

\subsection{Micro- and Nano-scale Delivery System}

In many applications, additional and sophisticated drying techniques like spray-drying, granulation, agglomeration, or specific powder-catch processes, are required to offer content uniformity, long-term storage stability, and optimal handling properties, such as free flowability without dust formation. Well-designed particulate delivery forms feature a granule or beadlet structure as illustrated in Fig. 1. In micro- and nano-scale delivery systems, internal phases of comminuted crystalline active ingredients or micronized droplets of lipophilic compounds are embedded in continuous matrix phases consisting of protective hydrocolloids with emulsifying properties, antioxidants, and further excipients that support stability and desired matrix properties, e.g. glass transition temperature $\left(\mathrm{T}_{\mathrm{g}}\right)$ and density. ${ }^{[28]}$ Typically, the content of active ingredients, such as vitamins or carotenoids, varies from $1-50 \%(\mathrm{w} / \mathrm{w})$, whereas hydrocolloids often represent the major fraction in the product composition ranging from 10-80\% (w/w). In brief, consumers are increasingly demanding clean-label foodstuffs and, consequently, compositions need to be based on naturally-derived ingredients, free from synthetic additives, free from materials of animal origin or other ethnic concerns, and, most importantly in view of environmental sustainability, based on renewable materials.

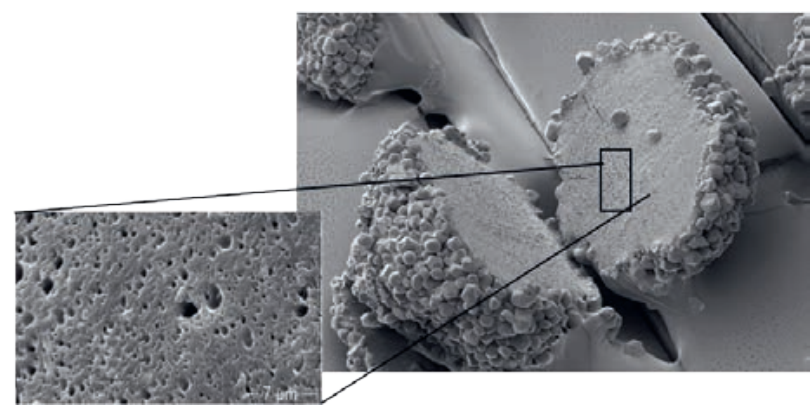

Fig. 1. Scanning electron micrograph of a cross-cut DSM beadlet. Corn starch on the particle surface improves flowability. The amplified crosssection shows dried matrix and embedded oil droplets with a size of $<1 \mu \mathrm{m}$. Scale-bar indicates $7 \mu \mathrm{m}$. Courtesy of DSM.

\subsection{Our Solutions}

Our teams at DSM Nutritional Products have already identified these trends more than two decades ago and we are now providing a broad variety of product forms of natural or natureidentical vitamins and carotenoids using emulsifying and stabilizing hydrocolloids that are based on natural and renewable sources. Our product portfolio offers sustainable and tailor-made products with a reduced environmental $(\mathrm{ECO}+)$ or a better social impact (People+) for highly diverse applications in animal and human nutrition. For instance, food and feed manufacturers have access to various vitamin and carotenoid product forms for vitamin fortification (foodstuffs and beverages in general, multi-vitamin tablets, capsules, feed premixes), coloration (foodstuffs, such as dairy products, confectionery, and beverages), and pigmentation (animal products, such as egg yolk and salmon). Product forms for human nutrition and health applications are mainly based on native starches and their derivatives, such as modified starches, maltodextrins, and glucose syrups, as well as pectin from various sources. Animal feed producers can count on our Carophyll carotenoid products forms based on formulations using renewable ingredients like lignosulfonates. In both cases, glucose rep- 
resents the starting material: Glucose is a monosaccharide that is biosynthesized in plants via photosynthesis and then transformed into either building material, such as cellulose, hemicelluloses, or lignin, or storage molecules like starch. Additional chemical and enzymatical reactions convert these natural biopolymers into tailor-made hydrocolloids suitable for specific applications in the feed and food industry. The following three examples illustrate specific renewable hydrocolloids and their use in the product form development of vulnerable vitamins and carotenoids to protect them against environmental factors (e.g. light and oxygen) for providing excellent stability and, at the same time, high bioavailability.

\section{Modified Starches}

\subsection{Background}

Starch is a polymeric carbohydrate that is naturally produced by photosynthesis in the vast majority of green plants, such as rice, wheat, maize, and potatoes, and acts as energy storage. Starch is by far the most consumed carbohydrate in the human diet and can be used as starting material for naturally-derived efficient emulsifiers for a broad variety of applications which will be explored below. Based on the highly abundant raw materials used and the relatively easy production, starch appears to be more cost-effective than comparable carbohydrate-based hydrocolloids, such as gum acacia. ${ }^{[29]}$ Moreover, starch can also fulfill dietary requirements, such as vegetarian, vegan, kosher, and halal..17]

\subsection{Chemical Structure}

Starch is a branched polymeric carbohydrate of glucose units with the general chemical formula $\left(\mathrm{C}_{6} \mathrm{H}_{10} \mathrm{O}_{5}\right)$ with $n$ being the number of $\mathrm{D}$-glucose monomers and the degree of polymerization ranging from a few hundred to millions of glucose monomers. ${ }^{[30]}$ Starch comprises two types of polymers: Amylose with an average molecular weight of $10^{5}-10^{6}$ is composed of linear $\alpha-(1 \rightarrow 4)$ bonds, which promotes the formation of a helix structure. In contrast, amylopectin with an average molecular weight of $\sim 10^{8}$ is composed of linear $\alpha-(1 \rightarrow 4)$ bonds but with several short branched $\alpha-(1 \rightarrow 6)$ links after $\sim 24-30$ glucose links. ${ }^{[17]}$ Both types of polymers are held together by inter- and intra-molecular links based on hydrogen bonds and hydrophobic bonds, resulting in a water-insoluble granule. The plant sources mainly determine

Scheme 1. The esterification principle of amylopectin with octenyl succinate anhydride (OSA). Adapted from Sweedman et al. ${ }^{[17]}$
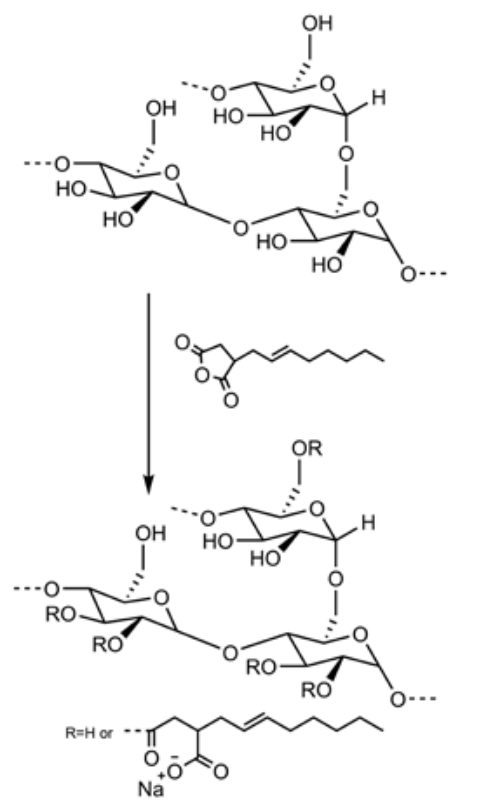

the arrangement of the molecules in these granules and lead to differences in physicochemical and morphological properties. ${ }^{[30]}$

Native starch has generally limited solubility in water and is not particularly surface-active. Therefore, it needs to be structurally modified to exhibit the desired techno-functional properties that are required to perform as an emulsifier. ${ }^{[17,31]}$ Starches can be modified depending on the required techno-functional properties by introducing, e.g. non-polar groups. Scheme 1 illustrates the esterification principle of the hydrophilic starch molecules with octenyl succinate anhydride (OSA) in mild alkaline conditions in order to generate highly surface-active molecules with increased hydrophobicity that may be used to stabilize the interface of hydrophilic and lipophilic phases in oil-in-water emulsions. ${ }^{[32]}$

Such OSA starch is a polyelectrolyte because of the free carboxylic acid groups in the OSA groups leading to negative charges at certain $\mathrm{pH}$ values contributing to the desired stabilization based on electrostatic repulsion. Furthermore, the emulsion is stabilized by introducing steric repulsion caused by the hydrophilic amylopectin chains protruding into the aqueous phase while the nonpolar side groups anchor the molecule to the droplet surface. ${ }^{[33]}$ Additionally, OSA starches tend to form highly viscoelastic films at the oil/water interface preventing re-agglomeration of the dispersed droplets. ${ }^{[32]}$ A commonly used parameter to characterize OSA starches is the degree of substitution, which is the average number of octenyl succinate derivatives per glucose unit. The most widely described synthesis pathway is a reaction in an aqueous medium under mild alkaline conditions with the starch in its granular form. The biological origin of the starch is mainly waxy maize, predominantly consisting of amylopectin.[17] Manufacturing high performing OSA modified starches can be achieved by designing the right OSA modification reaction ${ }^{[34,35]}$ and, subsequently, treating the OSA starch with suitable amylases or acids guaranteeing the necessary structural characteristics and the resulting surface activity. ${ }^{[36]}$ It is assumed that the introduced OSA groups are distributed in the interior as well as on the outside of the starch granule, and surface-activity may be improved by modifying the outside branches to make them more accessible. ${ }^{[32]}$ The selection of optimal OSA-starches for a given application may be facilitated by a better understanding of the relations between performance and molecular structure, and the mechanistic reasons for observed correlations. Nevertheless, structural parameters, including molecular size distribution, chain-length distribution, degree of branching, degree of substitution, and amount of small molecules such as maltose resulting from $\beta$-amylase activity, can be correlated with the functional properties, such as viscosity, droplet size, and stability of emulsions. ${ }^{[37,38]}$ For the modification on a commercial scale, these esters are prepared by the base-catalyzed reaction of granular starches in aqueous solutions and alkenyl succinic anhydrides under mild alkaline conditions ( $\mathrm{pH} \sim 8.5$ ). This groundbreaking modification based on esterification, nowadays typically using mild alkaline conditions ( $\mathrm{pH} \sim 8.5$ ) and mild temperatures $\left(\sim 35^{\circ} \mathrm{C}\right)$, was patented in the 1950 s and enabled the design of high-performance molecules by exploiting their amphiphilic character. ${ }^{[17]}$

\subsection{Application Examples}

OSA starches are approved as a food additive (E1450: Modified starch) quantum satis for most applications in the European Union and further benefit from global regulatory approval in a huge variety of applications. They have been extensively used to prepare aqueous emulsions and dried microencapsulated formulations of vitamins and carotenoids while exhibiting excellent performance and stability. Over the last decades, the number of publications investigating the optimization of OSA starch synthesis and characterization have increased significantly. Likewise, the patent landscape using OSA-starches broadened significantly, especially for fat-soluble vitamins and carotenoids. For instance, solid formu- 
lations of the carotenoids lutein and zeaxanthin were developed using high-performance wet-milling in OSA-starch matrices, showing superior performance and stability compared to product forms based on other biopolymers. ${ }^{[39,40]}$ Applications in which carotenoids such as lutein are encapsulated in aqueous ${ }^{[41]}$ and transparent ${ }^{[42]}$ oil-in-water emulsions stabilized by OSA starches are described in several patents.

\section{Pectin}

\subsection{Background}

Pectin is an anionic heteropolysaccharide primarily composed of partially methoxylated galacturonic acids ubiquitously present in the primary cell walls of plants. Pectin is typically derived from processing by-products of certain fruits and vegetables such as apple pomace, citrus peel, and sugar beet peel. ${ }^{[4]}$

\subsection{Chemical Structure}

Pectins consist of a linear backbone of $\alpha-1,4$ linked D-galacturonic acid units with partially derivatized methylated carboxyl and acetylated hydroxyl groups as shown in Scheme 2. Depending on the origin of pectin these chains are sometimes branched with neutral side chains of D-galactose, L-arabinose, and D-Xylose. ${ }^{[44,45]}$

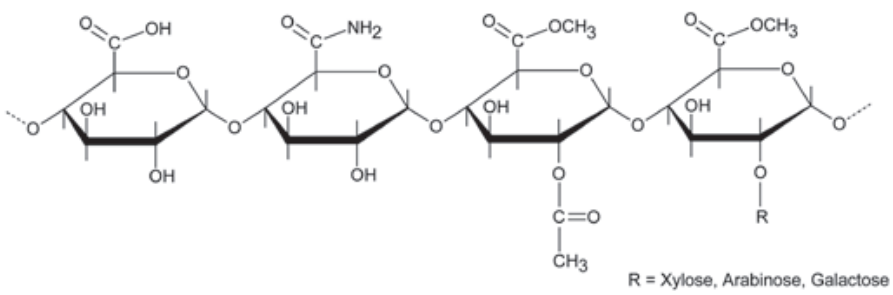

Scheme 2. Simplified scheme of pectin showing the $\alpha-1,4$ linked galacturonic acid chains with (from left to right) a carboxyl group at C5, an amidated carboxyl group at C5, a methylated carboxyl group (= methoxylated group) at C5, an acetylated hydroxyl group at C2, neutral sugars (R) at C2 and another methylated carboxyl group (=methoxylated group) at C5. Adapted from Pilnik. ${ }^{[46]}$

The composition and techno-functional properties of pectin depend primarily on origin, the extraction process, and downstream treatments and, therefore, lead to a wide range of methyl ester contents and degrees of neutralization, as well as functional groups. In large-scale production, all water-soluble substances are extracted using hot water after which the alcohol-insoluble pectin is precipitated using ethanol or isopropanol with subsequent centrifugation or filtration and washing steps. Targeted modification of the pectin molecules to modify techno-functional properties such as gel hardness, spreadability, and speed of gel formation can be achieved using hydrochloric acid to reduce the degree of esterification, or ammonia to form amidated pectin. While in nature $80 \%$ of the galacturonic acid carboxyl groups are esterified with methanol, processing conditions may alter these ratios yielding either i) high-methoxyl pectin (also known as high-esterified pectin) in which more than $50 \%$ of the carboxyl groups are in the methyl ester form $\left(-\mathrm{COOCH}_{3}\right)$ or ii) low-methoxyl pectin with a degree of esterification of 5-50\% in which the non-esterified galacturonic acid groups can be either free acid groups $(-\mathrm{COOH})$ or form salts such as sodium, potassium, or calcium. ${ }^{[44]}$ Highesterified pectin tends to form gels at acidic conditions of $\mathrm{pH} 1.5$ 3 and at sugar contents of $>55 \%$, while the low-esterified pectin tends to form gels in the presence of polyvalent ions such as calcium at a broader $\mathrm{pH}$ range of 1-7 also in the absence of sugar. ${ }^{[43]}$ Additionally, carboxymethyl groups can react with ammonia to prepare carboxylic acid amide known as amidated pectin, which is low-methoxyl pectin that tends to form a gel with sugar as well as polyvalent ions. ${ }^{[47]}$ Furthermore, pectin acids having a degree of esterification $<5 \%$ may be produced that gel similarly to lowmethoxyl pectin and precipitate at high $\mathrm{pH}$ values and high levels of polyvalent ions as pectates. ${ }^{[44]}$

As mentioned above, also the origin of the pectin influences its techno-functional properties: Sugar beet pectin with its complex structure exhibits a high surface activity and exhibits excellent emulsifying properties, which are mainly attributed to i) covalently bound glycoproteins such as the arabinogalactan proteins ${ }^{[48,49]}$ especially rich in hydrophobic hydroxyproline, ${ }^{[50]}$ ii) high levels of acetyl groups at the O-2 and O-3 position within the galacturonic backbone leading to a degree of acetylation of up to over $25 \%,{ }^{[51,52]}$ and iii) high levels of phenolic esters such as ferulic acid in the lateral chains. ${ }^{[50,53]}$ These hydrophobic groups enable to adsorb to oil-water interfaces and reduce the interfacial tension ${ }^{[54]}$ while especially an increased protein content leads to higher adsorption to the surface of the oil droplets. ${ }^{[5]}$ The formed pectin-based interfacial layer of the dispersed phase provides electrostatic and steric repulsion increasing its stability against flocculation and coalescence. ${ }^{[52,56]}$ Compared to other hydrocolloids such as gum Arabic lower amounts are required to stabilize emulsions. ${ }^{[53,57,58]}$ In contrast to sugar beet-derived pectin, citrus-derived pectin has a higher molecular size, a lower degree of acetylation, and a lower protein content leading to a rather low surface activity. ${ }^{[52,59]}$ Nevertheless, various sources for pectin derived from by-products are available on the market with each product aiming at different applications.

\subsection{Application Examples}

Based on the unique gelling properties in combination with $\mathrm{Ca}^{2+}$ ions or in solution at low $\mathrm{pH}$, pectin offers a variety of food application opportunities such as for confectionery, candy, and beverages. ${ }^{60]}$ In addition, the potential of pectin as wall material in the encapsulation of bioactive substances ${ }^{[61,62]}$ and its application for the stabilization of nanoemulsions ${ }^{[63]}$ has recently gained increased attention. For instance, sugar beet pectin was used to prepare dried carotenoid formulations for later application in instant powders for beverages and pudding. ${ }^{[64]}$ Moreover, intellectual property is available using pectin as encapsulating agent for carotenoid emulsions that showed sustained release for targeted delivery to the human colon. ${ }^{[65]}$

\section{Lignosulfonates}

\subsection{Background}

Lignosulfonates are the water-soluble salts of lignosulfonic acid, an anionic polymer composed of a sulfonated and highly crosslinked lignin. ${ }^{[27]}$ The lignin backbone is a complex phenolic biopolymer that is found as a constituent of the secondary cell walls of most plants and was traditionally used for lowvalue applications, such as burning for energy production. ${ }^{[66]}$ Nevertheless, lignin accumulates in large amounts during wood refinement and target-driven up-cycling enables the valorization to renewable emulsifiers for high-value applications as will be explored below. ${ }^{[26]}$

\subsection{Chemical Structure}

The basis of this side-stream refinement (see Scheme 10 of 'From Sugar into Nutritional Products - Active Ingredients' in ref. [1]) is the hydrophobic backbone lignin which is tightly bound to the other two main components of wood cell walls, i.e. cellulose and hemicelluloses. Chemically, the polyelectrolyte lignin is an amorphous and poly-branched network of the aromatic building block 4-hydroxyphenylpropanoid that can polymerize in a random arrangement, resulting in a large variety of molecular structures depending on its origin. ${ }^{[27]}$ Lignin can be extracted via a bio- 
mass separation step if required being further purified by removing residual carbohydrates. ${ }^{[67]}$ The subsequent high-temperature separation and modification process can either be sulfur-based or sulfur-free, each yielding a distinct lignin fraction. ${ }^{[68]}$ During this step, structural modifications of side chains and substructures of the backbone may occur, and sulfur as well as grafted functional groups such as phenolic hydroxyl and/or carboxyl groups may be introduced to obtain techno-functional lignosulfonates. The sulfur process can be done in acidic conditions ( $\mathrm{pH} 1-2)$ using sulfurous acid, which is referred to as lignosulfonate via sulfite pulping, or at basic conditions ( $\mathrm{pH} \sim 13$ ) using a mixture of sodium hydroxide and sodium sulfide, which is referred to as Kraft lignin via Kraft pulping. The sulfur-free process may be done using solvents such as acetic acid, water, or ethanol, which is referred to as organosolv lignin via solvent pulping, or at basic conditions $(\mathrm{pH}$ 12) using sodium hydroxide, which is referred to as soda lignin via soda pulping. ${ }^{[27,68]}$

\subsection{Application Examples}

Unlike typical surfactants having a one-dimensional structure with a hydrophilic head attached to the hydrophobic tail, ${ }^{[13]}$ lignosulfonates exhibit a highly surface-active poly-branched complex structure making them highly interesting for a variety of applications. ${ }^{[69]}$ Due to their polyelectrolytic attribute, lignosulfonates are water-soluble macromolecules comprising various ionizable functional groups at high abundance, such as sulfonate and carboxyl groups as shown in Scheme 3. ${ }^{[26,66]}$ In combination with its hydrophobic lignin backbone, lignosulfonates feature an amphiphilic character.[27]

Their capability to stabilize o/w emulsions across a wide range of acidic $\mathrm{pH}$ levels has been highlighted by Czaikoski et al. ${ }^{[70]}$ compared to the high $\mathrm{pH}$-sensitive application of protein-based emulsions. Furthermore, Ruwoldt et al. ${ }^{[71]}$ have reported enhanced emulsion stability at rising hydrophobicity of lignosulfonates concomitant with lower salt tolerance. In brief, depending on the source and the processing of lignosulfonates, there are tailor-made types available on the market that enable a broad range of industrial applications, e.g. as plasticizer (concrete), dispersant (drilling fluid thinner), and pigment stabilizer. ${ }^{[26]}$ Further details on tuning the performance of lignosulfonates depending on e.g. their molecular structure, origin, molecular weight distribution, and concentration have been reported by Mikkonen, ${ }^{[27]}$ Ruwolt, ${ }^{[26]}$ Czaikoski

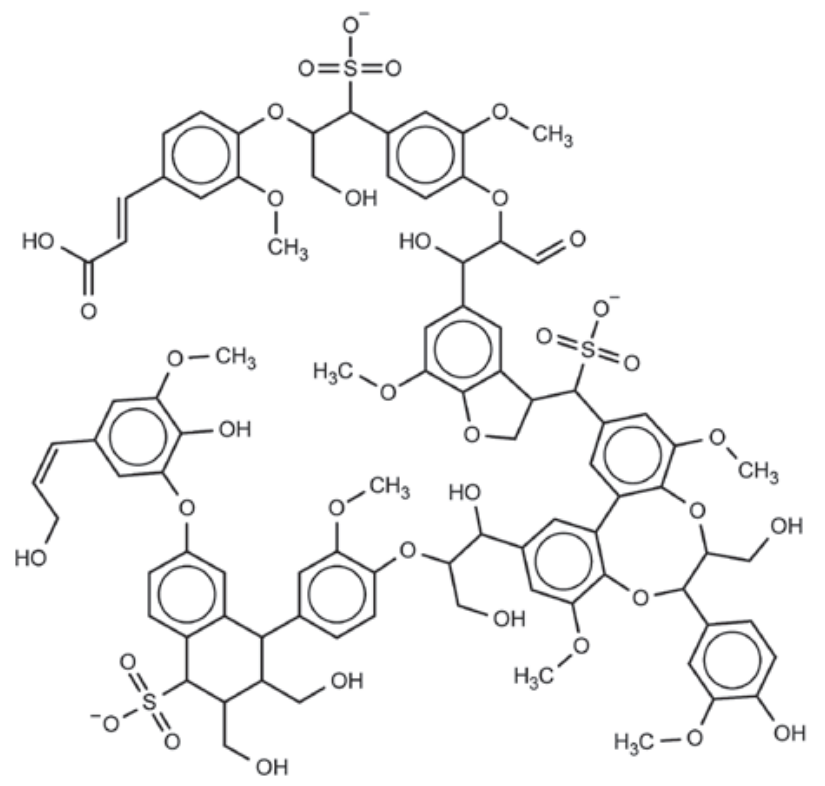

Scheme 3. Proposed molecular structure of lignosulfonate. Adapted from Kun and Pukánszky. ${ }^{[66]}$ et al. ${ }^{[70]}$ and Ruwolt et al. ${ }^{[71]}$ Most recently, the potential of lignosulfonates to function as a redox couple in redox flow batteries has been investigated, being a cheaper, renewable, and therefore a more sustainable alternative raw material to the commonly used toxic vanadium compounds. ${ }^{[72]}$ Over the past years, an impressive patent landscape has been established using lignosulfonates for formulating fat-soluble vitamins and carotenoids, in particular, canthaxanthin and astaxanthin for their application as feed additives for the pigmentation of egg yolk and the flesh of salmonids. ${ }^{[73-75]}$ Herein, lignosulfonates have functioned as potent colloidal stabilizers of highly bioavailable suspension- and emulsion-based delivery systems of carotenoids and their derivatives, ${ }^{[73,75]}$ or the biomass from the fermentation of, e.g. Yarrowia lipolytica. ${ }^{[76]}$ In combination with OSA-starches and further starch-degradation products, lignosulfonates have been used to form a dense emulsifying and protective matrix that increased the long-term stability of encapsulated carotenoids and fat-soluble vitamins. ${ }^{[74,77]}$ As a non-gelling matrix, lignosulfonate-based emulsions have required sophisticated process conduct at controlled drying conditions to transfer them into powdery product forms. ${ }^{[78]}$

\section{Conclusions}

The increasing interest in using naturally-derived ingredients for the formulation of active substances in order to satisfy consumer demands leads to new challenges in manufacturing microand nano-scale delivery systems and provides novel opportunities to produce stable and highly bioavailable product forms for their later use in various industrial applications. In-depth insights into the molecular basis and structure-function relationship of the used emulsifiers are essential for tailor-made and science-driven product form developments. Identifying new sources of naturally-derived emulsifiers will be of utmost importance to facilitate the formulation of our urgently required vitamins, carotenoids, and other active ingredients in versatile target applications for food, feed, and pharmaceutical purposes. Although we focused on renewable materials that serve as protective hydrocolloids for vitamins and carotenoids, the above-described formulation concepts may also be applied to further active ingredients like nutritional lipids.

\section{Acknowledgements}

We are grateful to Werner Bonrath and team (DSM Nutritional Products) for the continuous and inspiring impulses on developing sustainable routes and formulation processes for the production of active ingredients and application-specific product forms, respectively. We kindly acknowledge Veronika M. Lieb for her support in illustrating the chemical structures of Scheme 2 and 3.

Received: May 17, 2021

[1] W. Bonrath, H. Kroon, U. Létinois, M. Marty, O. May, M.A. Müller, J. Schütz, B. Wüstenberg, Chimia 2021, 75, 757, https://doi.org/10.2533/chimia.2021.757.

[2] S. P. Dhakal, J. He, Food Res. Int. 2020, 137, 109326 , https://doi.org/10.1016/j.foodres.2020.109326.

[3] A. J. Meléndez-Martínez, A. I. Mandić, F. Bantis, V. Böhm, G. I. A Borge, M. Brnčić, A. Bysted, M. P. Cano, M. G. Dias, A. Elgersma, M. Fikselová, J. García-Alonso, D. Giuffrida, V. S. S. Gonçalves, D. Hornero-Méndez, K. Kljak, V. Lavelli, G. A. Manganaris, P. MapelliBrahm, M. Marounek, B. Olmedilla-Alonso, M. J. Periago-Castón, A. Pintea, J. J. Sheehan, V. Tumbas Šaponjac, M. Valšíková-Frey, L. V. Meulebroek, N. O’Brien, Crit. Rev. Food Sci. Nutr. 2021, 1 , https://doi.org/10.1080/10408398.2020.1867959.

[4] R. Schex, F. Schweiggert, B. Wüstenberg, W. Bonrath, C. Schäfer, R. Schweiggert, J. Agric. Food Chem. 2020, 68, 5259, https://doi.org/10.1021/ acs.jafc.0c00933.

[5] S. Maghsoudi, B. Taghavi Shahraki, N. Rabiee, Y. Fatahi, M. Bagherzadeh, R. Dinarvand, S. Ahmadi, M. Rabiee, M. Tahriri, M. R. Hamblin, L. Tayebi, T. J. Webster, Crit. Rev. Food Sci. Nutr. 2021, 1 , https://doi.org/10.1080/10408398.2020.1867958. 
[6] L. Schweikert, in 'Sustainable Nutrition in a Changing World', Eds H. K. Biesalski, A. Drewnowski, J. T. Dwyer, J. J. Strain, P. Weber, M. Eggersdorfer, Springer International Publishing, Cham, 2017, p. 289.

[7] D. J. McClements, E. A. Decker, Y. Park, J. Weiss, Crit. Rev. Food Sci. Nutr. 2009, 49, 577, https://doi.org/10.1080/10408390902841529.

[8] B. M. Steiner, D. J. McClements, G. Davidov-Pardo, Trends Food Sci. Technol. 2018, 82, 71, https://doi.org/10.1016/j.tifs.2018.10.003.

[9] C. Christiansen, K. Fuchs, Patent Appl. No. EP2345336A1, 2011

[10] K. Koehler, J. Naud, Patent Appl. No. WO2016174004A1, 2016.

[11] E. Rinninella, M. Cintoni, P. Raoul, A. Gasbarrini, M. C. Mele, Int. J. Environ. Res. Public Health 2020, 17, 8816, https://doi.org/10.3390/ijerph17238816.

[12] J. S. Ribeiro, C. M. Veloso, Food Hydrocoll. 2021, 112, 106374, https://doi. org/10.1016/j.foodhyd.2020.106374.

[13] D. J. McClements, 'Food Emulsions: Principles, Practices, and Techniques', 3rd Edn., CRC Press, 2015

[14] M. C. Gómez-Guillén, B. Giménez, M. E. LópezCaballero, M. P. Montero, Food Hydrocoll. 2011, 25, 1813, https://doi.org/10.1016/j.foodhyd.2011.02.007.

[15] G. Stainsby, P. R. Saunders, A. G. Ward, J. Polym. Sci. 1954, 12, 325, https://doi.org/10.1002/pol.1954.120120127.

[16] A. A. Karim, R. Bhat, Trends Food Sci. Technol. 2008, 19, 644 https://doi.org/10.1016/j.tifs.2008.08.001

[17] M. C. Sweedman, M. J. Tizzotti, C. Schäfer, R. G. Gilbert, Carbohydr. Polym. 2013, 92, 905, https://doi.org/10.1016/j.carbpol.2012.09.040.

[18] M. Beck, B. Leuenberger, C. Schäfer, G. Wagner, C. Rebernig-Staiger, Patent No. WO2006053761A2, 2006 .

[19] E. Funda, B. Leuenberger, M. Beck, C. Schäfer, Patent No. EP1545244B1, 2007.

[20] J. D. Krill, Q. Tang, Patent Appl. No. WO2021013710A1, 2021.

[21] I. Paraman, N. S. Hettiarachchy, C. Schaefer, Cereal Chem. 2007, 84, 593, https://doi.org/10.1094/CCHEM-84-6-0593.

[22] I. Paraman, N. S. Hettiarachchy, C. Schaefer, M. I. Beck, Cereal Chem. 2007, 84, 343, https://doi.org/10.1094/CCHEM-84-4-0343.

[23] M. Beck, N. S. Hettiarachchy, B. H. F. Leuenberger, I. Paraman, C. Schaefer, G. Wagner, Patent No. US9133254B2, 2015.

[24] F. Runge, E. Lüddecke, H. Auweter, A. Pfeiffer, W. Hinz, Patent No. EP1219292B1, 2004

[25] Y. Cheng, P. Lu, C. Huang, J. Wu, J. Supercritical Fluids 2017, 130, 1246, https://doi.org/10.1016/j.supflu.2016.12.021

[26] J. Ruwoldt, Surfaces 2020, 3, 622, https://doi.org/10.3390/surfaces3040042.

[27] K. S. Mikkonen, Green Chem. 2020, 22, 1019, https://doi.org/10.1039/ C9GC04457D

[28] D. J. Hughes, G. B. Bönisch, T. Zwick, C. Schäfer, C. Tedeschi, B. Leuenberger, F. Martini, G. Mencarini, M. Geppi, M. A. Alam, J. Ubbink, Carbohydr. Polym. 2018, 199, 1, https://doi.org/10.1016/j.carbpol.2018.06.056.

[29] P. Dokić, L. Dokić, T. Dapčević, V. Krstonošić, in 'Colloids for Nano- and Biotechnology', Eds. Z. D. Hórvölgyi, É Kiss, Springer, Berlin, Heidelberg, 2008, p. 48.

[30] J. F. Robyt, in 'Glycoscience: Chemistry and Chemical Biology', Eds. B. O. Fraser-Reid, K. Tatsuta, J. Thiem, Springer, Berlin, Heidelberg, 2008, p. 1437.

[31] B. Kaur, F. Ariffin, R. Bhat, A. A. Karim, Food Hydrocoll. 2012, 26, 398 , https://doi.org/10.1016/j.foodhyd.2011.02.016.

[32] R. L. Shogren, A. Viswanathan, F. Felker, R. A. Gross, Starch 2000, 52, 196 , https://doi.org/10.1002/1521-379X(200007)52:6/73.0.CO;2-4.

[33] R. Chanamai, D. J. McClements, J. Food Sci. 2002, 67, 120 , https://doi.org/10.1111/j.1365-2621.2002.tb11370.x.

[34] M. C. Sweedman, C. Schäfer, R. G. Gilbert, Carbohydr. Polym. 2014, 111, 918, https://doi.org/10.1016/j.carbpol.2014.04.088

[35] M. C. Sweedman, J. Hasjim, C. Schäfer, R. G. Gilbert, Carbohydr. Polym. 2014, 112, 85, https://doi.org/10.1016/j.carbpol.2014.05.067.

[36] M. C. Sweedman, J. Hasjim, M. J. Tizzotti, C. Schäfer, R. G. Gilbert, Carbohydr. Polym. 2013, 97, 9, https://doi.org/10.1016/j.carbpol.2013.04.041.

[37] H. Zhang, C. Schäfer, P. Wu, B. Deng, G. Yang, E. Li, R. G. Gilbert, C. Li, Food Hydrocoll. 2018, 74, 168, https://doi.org/10.1016/j.foodhyd.2017.08.009.

[38] H. Han, H. Zhang, E. Li, C. Li, P. Wu, Food Hydrocoll. 2019, 90, 132, https://doi.org/10.1016/j.foodhyd.2018.12.011

[39] M. Beck, A. Estrella, E. Funda, A. Hitzfeld, C. Schäfer, B. Schlegel, K. Urban, Patent No. EP3435786B1, 2020.

[40] B. H. Leuenberger, B. Schlegel, K. M. Voelker, Patent No. EP1964479B1, 2013.

[41] M. Beck, H. Grass, B. H. Leuenberger, M. Nowotny, C. Schaefer, K. M. Voelker, Patent No. EP1940249B1, 2015.

[42] T. Helgason, C. Köpsel, C. Sambale, A. Habich, A. Hasse, Patent No. EP2687103B1, 2019.

[43] S. Y. Chan, W. S. Choo, D. J. Young, X. J. Loh, Carbohydr. Polym. 2017, 161 , 118, https://doi.org/10.1016/j.carbpol.2016.12.033.

[44] B. Zeeb, M. Roth, H. Endreß, in 'Handbook of Hydrocolloids (Third Edition)', Eds. G. O. Phillips, P. A. Williams, Woodhead Publishing, Sawston, Cambrigde, 2021, p. 295

[45] D. Mohnen, Curr. Opin. Plant Biol. 2008, 11, 266 , https://doi.org/10.1016/j.pbi.2008.03.006.
[46] W. Pilnik, in 'Lebensmitteltechnologie: Biotechnologische, Chemische, Mechanische Und Thermische Verfahren Der Lebensmittelverarbeitung', Eds. R. Heiss (Ed.), Springer, Berlin, Heidelberg, 1991, p. 228.

[47] J. Chen, W. Liu, C. Liu, T. Li, R. Liang, S. Luo, Crit. Rev. Food Sci. Nutr. 2015 , 55, 1684, https://doi.org/10.1080/10408398.2012.718722.

[48] E. D. Ngouémazong, S. Christiaens, A. Shpigelman, A. Van Loey, M. Hendrickx, Compr. Rev. Food Sci. Food Saf. 2015, 14, 705, https://doi.org/10.1111/1541-4337.12160.

[49] P. A. Williams, C. Sayers, C. Viebke, C. Senan, J. Mazoyer, P. Boulenguer, J. Agric. Food Chem. 2005, 53, 3592, https://doi.org/10.1021/jf0404142.

[50] J. Leroux, V. Langendorff, G. Schick, V. Vaishnav, J. Mazoyer, Food Hydrocoll. 2003, 17, 455, https://doi.org/10.1016/S0268-005X(03)00027-4.

[51] F. M. Rombouts, J. Thibault, Carbohydr. Res. 1986, 154, 177, https://doi.org/10.1016/S0008-6215(00)90031-4.

[52] U. S. Schmidt, L. Koch, C. Rentschler, T. Kurz, H. U. Endreß, H. P. Schuchmann, Food Biophysics 2015, 10, 217 https://doi.org/10.1007/s11483-014-9380-1.

[53] T. Funami, M. Nakauma, S. Ishihara, R. Tanaka, T. Inoue, G. O. Phillips, Food Hydrocoll. 2011, 25, 221, https://doi.org/10.1016/j.foodhyd.2009.11.017.

[54] İ Gülseren, M. Corredig, Food Hydrocoll. 2014, 34, 154, https://doi.org/10.1016/j.foodhyd.2012.11.015.

[55] C. K. Siew, P. A. Williams, S. W. Cui, Q. Wang, J. Agric. Food Chem. 2008, 56 , 8111, https://doi.org/10.1021/jf801588a.

[56] H. Chen, S. Qiu, J. Gan, Y. Liu, Q. Zhu, L. Yin, Food Hydrocoll. 2016, 57, 262 , https://doi.org/10.1016/j.foodhyd.2016.02.005.

[57] L. Bai, S. Huan, Z. Li, D. J. McClements, Food Hydrocoll. 2017, 66, 144, https://doi.org/10.1016/j.foodhyd.2016.12.019.

[58] M. Li, D. J. McClements, X. Liu, F. Liu, Compr. Rev. Food Sci. Food Saf. 2020, 19,3159 , https://doi.org/10.1111/1541-4337.12622.

[59] S. H. E. Verkempinck, C. Kyomugasho, L. Salvia-Trujillo, S. Denis, M. Bourgeois, A. M. Van Loey, M. E. Hendrickx, T. Grauwet, Food Hydrocoll. 2018, 85, 144, https://doi.org/10.1016/j.foodhyd.2018.07.014.

[60] B. R. Thakur, R. K. Singh, A. K. Handa, M. A. Rao, Crit. Rev. Food Sci. Nutr. 1997, 37, 47, https://doi.org/10.1080/10408399709527767.

[61] A. Rehman, T. Ahmad, R. M. Aadil, M. J. Spotti, A. M. Bakry, I. M. Khan, L. Zhao, T. Riaz, Q. Tong, Trends Food Sci. Technol. 2019, 90, 35, https://doi.org/10.1016/j.tifs.2019.05.015

[62] M. Manzoor, J. Singh, J. D. Bandral, A. Gani, R. Shams, Int. J. Biol. Macromol. 2020, 165, 554, https://doi.org/10.1016/j.ijbiomac.2020.09.182.

[63] T. E. Mungure, S. Roohinejad, A. E. Bekhit, R. Greiner, K. Mallikarjunan, Curr. Opin. Food Sci. 2018, 19, 72, https://doi.org/10.1016/j.cofs.2018.01.011

[64] M. I. Beck, K. Kuhny, B. Leuenberger, Patent No. EP1416810B1, 2009.

[65] R. Carle, A. Schieber, S. Mutter, Patent No. EP1587375B1, 2019.

[66] D. Kun, B. Pukánszky, Eur. Polym. J. 2017, 93, 618 , https://doi.org/10.1016/j.eurpolymj.2017.04.035.

[67] S. S. Hassan, G. A. Williams, A. K. Jaiswal, Bioresour. Technol. 2018, 262 310, https://doi.org/10.1016/j.biortech.2018.04.099.

[68] S. Laurichesse, L. Avérous, Prog. Polym. Sci. 2014, 39, 1266, https://doi.org/10.1016/j.progpolymsci.2013.11.004

[69] B. O. Myrvold, Ind. Crops Prod. 2008, 27, 214 , https://doi.org/10.1016/j.indcrop.2007.07.010.

[70] A. Czaikoski, A. Gomes, K. C. Kaufmann, R. B. Liszbinski, M. B. de Jesus, R. L. da Cunha, Ind. Crops Prod. 2020, 154, 112762, https://doi.org/10.1016/j.indcrop.2020.112762.

[71] J. Ruwoldt, J. Planque, G. Øye, ACS Omega 2020, 5, 15007, https://doi.org/10.1021/acsomega.0c00616.

[72] D. Rosenberg, W. Jansen, Nachrichten aus der Chemie 2021, 69, Februar, 14

[73] E. Funda, Patent No. EP1788897B2, 2019.

[74] S. Rider, C. Schaefer, R. Schex, V. Verlhac, T. Zwick, Patent Appl. No. WO2021069733A1, 2021

[75] S. Rider, C. Schaefer, R. Schex, B. Schlegel, V. Verlhac, T. Zwick, Patent Appl. No. WO2021069753A1, 2021.

[76] D. Greenfell-Lee, C. Schäfer, J. Treganowan, C. Santos, Patent Appl. No. WO2015082688A1, 2015.

[77] C. Schaefer, R. Schex, C. Tsekou, T. Zwick, Patent Appl. No WO2021069752A1, 2021

[78] D. Schaffner, Patent No. EP1581065B1, 2007.

\section{License and Terms}

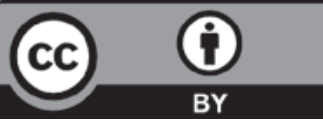

This is an Open Access article under the terms of the Creative Commons Attribution License CC BY 4.0. The material may not be used for commercial purposes.

The license is subject to the CHIMIA terms and conditions: (http:// chimia.ch/component/sppagebuilder/?view=page\&id=12).

The definitive version of this article is the electronic one that can be found at https://doi.org/10.2533/chimia.2021.766 